\title{
ANALISIS PENGARUH PEMBEBANAN TERHADAP EFISIENSI DAN SUSUT UMUR TRANSFORMATOR STEP UP 6kV / 70kV DI PLTU SUMBAWA BARAT UNIT 1 DAN 2 2×7 MW PT.PLN (PERSERO) UPK TAMBORA
}

\author{
Ilham Bayu Tiasmoro', Wirentake ${ }^{2}$, Paris Ali Topan ${ }^{3}$ \\ ${ }^{1^{*}}$ Fakultas Rekayasa Sistem Universitas Teknologi Sumbawa \\ 2,3Fakultas Rekayasa Sistem Universitas Teknologi Sumbawa
}

*Corresponding Author email: ${ }^{1}$ ilham.yiasmoro@gmail.com, ${ }^{2}$ wirentake@uts.ac.id, ${ }^{3}$ paris.ali.topan@uts.ac.id

\begin{tabular}{|c|c|}
\hline & Abstrak \\
\hline $\begin{array}{l}\text { Keyword : } \\
\text { PLTU, Pengaruh } \\
\text { Pembebanan, } \\
\text { Efisiensi, Susut } \\
\text { Umur, } \\
\text { Transformator }\end{array}$ & $\begin{array}{l}\text { Penelitian ini bertujuan untuk mengetahui besar faktor beban yang fluktuatif terhadap } \\
\text { efisiensi dan susut umur (loss of life) transformator } 6 \mathrm{kV} / 70 \mathrm{kV} \text { serta mengetahui besar } \\
\text { beban optimal agar mendapatkan efisiensi terbaik dan meminimalisir susut umur (Loss } \\
\text { of Life). Adapun metode yang digunakan dalam penelitian ini adalah metode penelitian } \\
\text { kuantitatif. Hasil penelitian menunjukkan bahwa efisiensi tertinggi PLTU Unit } 1 \text { ada di } \\
\text { angka 93,3\% dengan output daya } 5,8 \mathrm{MW} \text { dan daya input } 6,21 \mathrm{MW} \text { sedangkan yang } \\
\text { paling rendah ada di angka } 83,9 \% \text { dengan output daya } 5,5 \mathrm{MW} \text { dan daya input } 6,55 \\
\text { MW. Efisiensi tertinggi PLTU Unit } 2 \text { ada di angka } 95,7 \% \text { dengan output daya } 5,5 \mathrm{MW} \\
\text { dan daya input } 5,75 \mathrm{MW} \text { sedangkan yang paling rendah ada di angka } 61,03 \% \text { dengan } \\
\text { output daya } 3,3 \mathrm{MW} \text { dan daya input } 5,41 \mathrm{MW} \text {. Sementara susut umur transformator } \\
\text { Unit } 1 \text { PLTU Sumbawa Barat adalah } 0,0469 \text { jam/hari dengan rata-rata beban } 5,8 \mathrm{MW} \\
\text { sedangkan untuk Unit } 2 \text { adalah } 0,0311 \text { jam/hari dengan rata-rata beban } 5,2 \text { MW. Besar } \\
\text { kecilnya susut umur transformator tergantung dari pembebanan yang diberikan, makin } \\
\text { besar beban maka makin besar pula susut umurnya. Dalam hal ini memang untuk Unit } \\
1 \text { dibebani lebih tinggi daripada Unit } 2 \text { sehingga terlihat bahwa susut umur } \\
\text { transformator Unit } 2 \text { lebih kecil. Sedangkan Beban optimal pada PLTU ada di posisi } 80- \\
85 \% \text { dari daya mampunya. Hasil penelitian ini diharapkan dapat menjadi bahan } \\
\text { pertimbanagn bagi pltu Sumbawa untuk sebaiknya melakukan pemerataan dan } \\
\text { pengoptimalan beban agar tidak terjadi timpang antara kapasitas transformator dengan } \\
\text { daya yang diproduksi serta melakukan pemeliharaan transformator secara rutin guna } \\
\text { mengurangi losses yang terjadi. }\end{array}$ \\
\hline
\end{tabular}

\section{PENDAHULUAN}

PT. PLN (Persero) adalah perusahaan listrik nasional yang bergerak dibidang bisnis mulai dari pembangkit, transmisi, dan distribusi. Proyek bisnis dimulai dari Sabang sampai Merauke dan pulau-pulau kecil di Indonesia. Kewajiban PLN adalah menerangi seluruh nusantara termasuk pulau-pulau terluar Indonesia. Sistem PLN sangat komplek mulai dari interkoneksi seluruh pembangkit sampai bahkan ada yang terisolir (Choiri, 2017). Kebutuhan akan energi listrik saat ini menjadi prioritas utama masyarakat di dalam kehidupan sehari hari. Maka dari itu, kehandalan sistem dan pembangkit listrik mutlak harus dijaga demi pelayanan yang prima, terutama di wilayah kerja PT. PLN (Persero) Unit Pelaksana Pembangkitan (UPK) Tambora, karena UPK tersebut merupakan pembangkit base load yang diharapkan kehandalannya untuk tetap mengaliri listrik ke seluruh pulau Sumbawa.

UPK Tambora membawahi beberapa unit layanan pembangkit, antara lain; pembangkit diesel, pembangkit uap, pembangkit mesin gas, dan pembangkit mikro hidro. Unit Layanan Pembangkit Uap yang berada dibawah UPK Tambora adalah PLTU Sumbawa Barat. PLTU
Sumbawa Barat merupakan pembangkit listrik tenaga uap yang terletak di Desa Kertasari Kecamatan Taliwang Kabupaten Sumbawa Barat. Pembangkit listrik tersebut terdiri dari 2 unit pembangkit dengan kapasitas masing-masing 7 MW menggunakan batubara kalori rendah \pm 3800 $\mathrm{kcal} / \mathrm{kg}$.

Energi listrik yang dihasilkan untuk memenuhi kebutuhan listrik di sistem Sumbawa. disalurkan melalui jaringan transmisi SUTT $70 \mathrm{KV}$ dari switchyard di pembangkit ke pusat beban di Gardu Induk Taliwang. Dengan sudah tersambungnya sistem interkoneksi antar pulau Sumbawa dari Taliwang sampai dengan Sape maka PLTU Sumbawa Barat merupakan pembangkit base load yang diharapkan kehandalannya untuk tetap mengaliri listrik ke seluruh pulau Sumbawa.

Pola pembebanan yang dilayani oleh PLTU Sumbawa Barat bersifat fluktuatif, karena sebagian besar konsumsi energi listrik di pulau Sumbawa diperuntukkan kepada pelanggan sektor rumah tangga. Beban yang bersifat fluktuatif ini menimbulkan rugi-rugi pada transformator. Ketika suatu transformator diberi energi akan timbul rugirugi inti, rugi-rugi kumparan dan rugi-rugi bocor merupakan sumber panas dan menyebabkan 
kenaikan suhu kumparan dan minyak transformator (Srinivasan \& Krishnan, 2012). Kinerja transformator daya ditentukan melalui parameter rugi-rugi daya (losses) yang terjadi pada transformator (Ervianto \& Rizky, 2019). Jika terjadi rugi-rugi pada inti besi dapat menyebabkan timbulnya panas dan getaran yang berlebih pada transformator sehingga menyebabkan nilai efisiensi dan usia pakai transformator (Loss of Life) menjadi berkurang.

Adapun tujuan dari penelitian ini yakni untuk mengetahui besar faktor beban yang fluktuatif terhadap efisiensi dan susut umur (loss of life) transformator $6 \mathrm{kV} / 70 \mathrm{kV}$ serta mengetahui besar beban optimal agar mendapatkan efisiensi terbaik dan meminimalisir susut umur (Loss of Life)

\section{LANDASAN TEORI}

\section{Pengertian Umum Transformator}

Transformator merupakan suatu peralatan mesin listrik statis yang beroperasi dengan induksi elektromagnetik. Transformator berfungsi untuk menyuplai energi dari satu rangkaian listrik ke rangkaian listrik lainnya, dimana perbandingan tegangan antara sisi primer dan sekunder berbanding lurus dengan perbandingan jumlah lilitan dan berbanding terbalik dengan perbandingan arusnya (Wijaya, 2001).

\section{Prinsip Kerja Transformator}

Sebuah transformator sederhana pada dasarnya terdiri dari 2 kumparan yaitu kumparan primer dan kumparan sekunder. Pada kebanyakan transformator, kumparan ini dililitkan pada sebuah inti. Seperti terlihat pada Gambar di bawah.

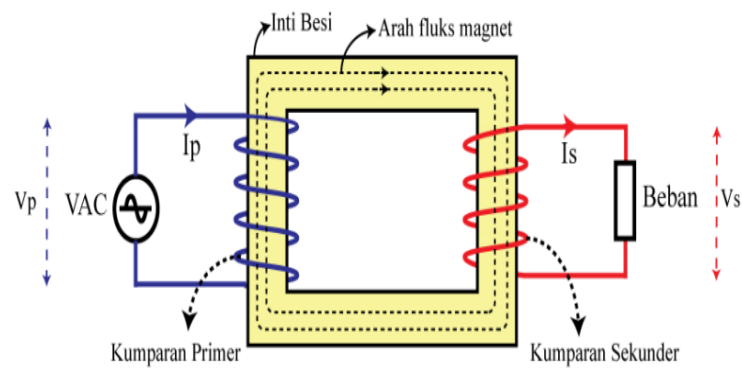

Gambar Prinsip Kerja Transformator

Apabila kumparan primer dihubungkan pada sumber tegangan yang bolak-balik, maka fluks bolak-balik ini akan muncul di dalam inti (core) dan membentuk jaringan tertutup (close loop), maka mengalirlah arus primer. Akibat adanya fluks pada kumparan primer, maka dikumparan primer terjadi induksi (self induction). Selain itu, juga terdapat induksi dikumparan sekunder karena pengaruh kumparan primer (mutual induction) sehingga menyebabkan munculnya fluks magnet pada kumparan sekunder.
Jika rangkaian sekunder dibebani energi listrik dapat disalurkan secara menyeluruh (Zuhal, 1995).

\section{Susut Umur Transformator (Loss of Life)}

Pada saat transformator memikul beban, semakin besar beban yang dipikul transformator semakin besar pula susut umurnya, demikian juga sebaliknya semakin kecil beban yang dipikul transformator maka semakin kecil pula susut umur pada transformator tersebut. Hal ini berkaitan dengan kenaikan temperatur pada inti transformator dan belitan kawat. Dimana kenaikan beban berbanding lurus dengan kenaikan temperatur inti transformator dan belitan kawat. Besar susut umur pada transformator karena pengaruh isolasi belitan saja tanpa memperhitungkan pengaruh yang lain dapat ditentukan sebagai berikut (Najdenkoski dkk, 2007)

Keterangan:

$$
L=\frac{1}{N} \sum_{n=1}^{N} X_{n}
$$

$$
\begin{aligned}
\mathrm{L} \quad= & \text { Susut umur (jam) } \\
X n \quad= & \text { Laju penuaan Thermal relative } \\
& \text { pada jam ke- } n \text { dikalikan } \\
& \text { dengan waktu operasional } \\
& \text { transformator }
\end{aligned}
$$

\section{Efisiensi Transformator}

Efisiensi transformator adalah perbandingan antara daya listrik yang keluar dari transformator (out) dengan daya listrik yang masuk pada transformator (in), transformator yang ideal efisiensinya $100 \%$ akan tetapi pada kenyataannya efisiensi transformator kurang dari $100 \%$. Hal ini dikarenakan rugi-rugi yang telah dijelaskan diatas sehingga energi listrik menjadi energi panas atau gerak. Efisiensi transformator dinyatakan dalam persamaan :

$$
\eta=\frac{P_{\text {out }}}{P_{\text {in }}} \times 100 \%
$$

Dengan:

$$
\begin{array}{ll}
\eta & =\text { Efisiensi } \\
P_{\text {out }} & =\text { Daya Keluar } \\
P_{\text {in }} & =\text { Daya Masuk }
\end{array}
$$

\section{METODE PENELITIAN}

Metode penelitian yang digunakan dalam penulisan penelitian ini adalah dengan metode kuantitatif. Menurut Amiruddin (2010) Penelitian kuantitaif adalah penelitian yang dilakukan dengan pengumpulan data dan menggunakan daftar pertanyaaan berstruktur (angket) yang disusun berdasarkan pengukuran terhadap variabel yang diteliti yang kemudian menghasilkan data kuantitatif. Sementara menurut Sugiyono (2011) penelitian kuantitatif adalah penelitian berupa 
angka-angka dan analisis analisis menggunakan statistik. Sedangkan menurut Ahmad Suyitno dan Tanzeh (2006), yang dimaksud penelitian kuantitatif adalah penelitian yang menitik beratkan pada penyajian data yang berbentuk angka atau kualitatif yang diangkakan (skoring) yang menggunakan statistik. Dengan kata lain, dalam penelitian kuantitatif peneliti berangkat dari sebuah teori (menguji sebuah teori) menuju data dalam bentuk angka dan berakhir pada penerimaan atau penolakan dari teori yang telah diuji kebenarannya. Penelitian kuantitatif bertumpu sangat kuat pada pengumpulan data. Data yang dimaksud berupa data yang diperoleh dari hasil pembacaan titik transaksi untuk dimasukan dilakukan perhitungan dan analisa.

\section{Metode Pengumpulan Data}

Metode pengumpulan data yang digunakan dalam penelitian ini dilakukan dengan membagi jenis data yang dikumpulkan menjadi 2 jenis, yakni data primer dan data sekunder.

Data Primer adalah data yang dikumpulkan dan diolah sendiri oleh peneliti langsung dari subjek atau objek penelitian yaitu Pembangkit Listrik Tenaga Uap (PLTU) Sumbawa Barat, tepatnya di kantor PLTU Sumbawa Barat. Untuk mendapatkan data primer ini digunakan metode wawancara yang dilakukan dengan pihakpihak terkait dan juga pengambilan data langsung di lapangan. Sementara Data Sekunder adalah data yang didapatkan tidak secara langsung dari objek atau subjek penelitian. Dalam metode ini, data diperoleh melalui referensi-referensi dari berbagai macam buku dan literatur yang berkaitan dengan permasalahan yang diambil.

\section{Tahapan Penelitian}

1. Identifikasi Masalah dan Studi Literatur

Tahap awal yang dilakukan pada penelitian ini adalah mengidentifikasi dan merumuskan masalah. Setelah rumusan masalahnya diformulasikan barulah dilanjutkan ke tahap selanjutnya yakni melakukan studi literatur. Studi literatur dilakukan dengan mengumpulkan informasi terkait dengan topik bahasan yang akan dibahas. Literatur- literatur yang didapatkan diperoleh dari laporan penelitian, thesis, buku-buku, dan sumber-sumber lainnya baik dari media cetak maupun internet atau bahkan penelitian sebelumnya yang sudah pernah dilakukan di PLTU Sumbawa Barat.

2. Studi Lapangan dan Pengumpulan Data Pada tahapan ini penelitian dilakukan dengan melakukan pengamatan dan observasi secara langsung ke lapangan dimana lokasi tempat penelitian yaitu di Pusat Listrik Tenaga Uap (PLTU) Sumbawa Barat 2x7 MW di Desa Labuhan Kertasari, Kecamatan Taliwang, Kabupaten Sumbawa Barat - NTB. Data-data yang didapatkan dari lapangan adalah data setiap jam operasi PLTU seperti; daya gross, daya net, daya auxiliary, daya reaktif, temperatur oli trafo, LV winding temperature dan daya beban gardu induk.

3. Menghitung Loss of Life Transformator Setelah mendapatkan data yang sudah disesuaikan dengan kebutuhan penelitian, kemudian dilakukan perhitungan usia pakai transformator (Loss of Life) sesuai dengan metode dan perumusan yang terkait. Untuk melakukan perhitungan susut umur transformator menggunakan standar IEC354 terdapat beberapa tahap, yaitu: menghitung ratio pembebanan dan perbandingan rugi yang kemudian digunakan untuk menghitung kenaikan temperature stabil Top Oil serta kenaikan temperatur Top Oil. Dari persamaan ratio pembebanan yang diperoleh selanjutnya dilakukan perhitungan untuk menentukan selisih temperatur antara Hot Spot dengan Top Oil. Kemudian dari persamaan kenaikan temperatur Top Oil dan selisih temperatur antara Hot Spot dengan Top Oil yang diperoleh dilakukan perhitungan temperatur Hot Spot dengan menggunakan data temperatur lingkungan. Selanjutnya berdasarkan hasil persamaan perhitungan temperatur Hot Spot maka laju penuaan Thermal relatif dapat dihitung dengan menggunakan metode IEC354 yang kemudian hasilnya digunakan untuk menghitung pengurangan umur transformator daya. Setelah dilakukannya tahapan perhitungan tersebut, maka didapatkan susut umur dari transformator yang digunakan pada PLTU Sumbawa Barat yang berkapasitas 10 MVA.

4. Menghitung Efisiensi Transformator Selanjutnya setelah dilakukan perhitungan usia pakai (Loss of Life) transformator kemudian dilakukan perhitungan efisiensi transformator berdasarkan data beban yang diproduksi dan juga data beban yang termonitor di Gardu Induk PLTU Sumbawa selama 24 jam terakhir dan mencari pada beban berapakah yang mempunyai efisiensi paling baik.

\section{HASIL DAN PEMBAHASAN}

Data Teknik PLTU Sumbawa Barat Unit 1 dan 2

Untuk dapat mencari susut umur dan juga efisiensi transformator pada penelitian ini didapatkan terlebih dahulu data real time kondisi pembangkit yang bisa diambil dari Control Room. Data yang diambil adalah pada tanggal 18 Juni 2020 dimana PLTU Sumbawa Barat beroperasi 2 unit dimana pada bulan sebelumnya hanya beroperasi 1 unit dikarenakan sedang dilaksanakannya overhaul pada unit 1. Adapun data teknik yang didapatkan adalah sebagai berikut: 
Tabel Data Teknik PLTU Sumbawa Barat Unit 1

\begin{tabular}{|c|c|c|c|c|c|c|c|c|c|}
\hline \multicolumn{10}{|c|}{ PLTUUnit1 } \\
\hline & \multicolumn{5}{|c|}{ Power Generator } & \multicolumn{3}{|c|}{ Transformator } & \multirow[b]{2}{*}{$\begin{array}{l}\text { Winding } \\
\text { Avg }\left({ }^{\circ}\right)\end{array}$} \\
\hline & $\begin{array}{l}\text { PGross } \\
(\mathrm{kW})\end{array}$ & $\begin{array}{l}\text { PSemu } \\
\text { (KVA) }\end{array}$ & P Nett (KW) & $\begin{array}{c}\text { PReartive } \\
\text { (kVar) }\end{array}$ & PAux (KW) & $\begin{array}{l}\text { Oil Temp } \\
\text { (C) }\end{array}$ & $\mid \begin{array}{c}\text { LW Winding } \\
\left({ }^{\circ} \mathrm{C}\right)\end{array}$ & $\begin{array}{c}\text { HW Winding } \\
\left.{ }^{\circ} \mathrm{C}\right)\end{array}$ & \\
\hline 01.00 & 6434 & 6518 & 5934 & 1025 & 500 & 49 & 47 & 47 & 47 \\
\hline 02,00 & 6411 & 6510 & 5911 & 999 & 500 & 48 & 46 & 47 & 46.5 \\
\hline 03.00 & 6226 & 6240 & 5726 & 967 & 500 & 48 & 46 & 46 & 46 \\
\hline 04.00 & 6653 & 6672 & 6153 & 764 & 500 & 47 & 46 & 45 & 45.5 \\
\hline 05.00 & 6555 & 6591 & 6055 & 767 & 500 & 47 & 46 & 45 & 45.5 \\
\hline 06.00 & 6308 & 6330 & 5808 & 1090 & 500 & 47 & 45 & 45 & 45 \\
\hline 07.00 & 6404 & 6530 & 5904 & 1001 & 500 & 47 & 45 & 45 & 45 \\
\hline 08.00 & 6127 & 6229 & 5627 & 1150 & 500 & 47 & 46 & 45 & 45.5 \\
\hline 09.00 & 6176 & 6264 & 5676 & 1255 & 500 & 48 & 47 & 46 & 46.5 \\
\hline 10.00 & 6214 & 6327 & 5714 & 1319 & 500 & 49 & 48 & 48 & 48 \\
\hline 11.00 & 6420 & 6549 & 5920 & 1454 & 500 & 51 & 50 & 49 & 49.5 \\
\hline 12.00 & 6459 & 6590 & 5959 & 1306 & 500 & 52 & 52 & 51 & 51.5 \\
\hline 13.00 & 6138 & 6330 & 5638 & 1552 & 500 & 53 & 52 & 53 & 52.5 \\
\hline 14.00 & 6250 & 6408 & 5750 & 1641 & 500 & 54 & 54 & 53 & 53.5 \\
\hline 15.00 & 6483 & 6812 & 5983 & 1379 & 500 & 54 & 53 & 53 & 53 \\
\hline 16.00 & 6178 & 6383 & 5678 & 1366 & 500 & 54 & 53 & 53 & 53 \\
\hline 17.00 & 6664 & 6760 & 6164 & 1395 & 500 & 53 & 52 & 51 & 51.5 \\
\hline 18.00 & 6158 & 6307 & 5658 & 1655 & 500 & 52 & 50 & 51 & 50.5 \\
\hline 19.00 & 6436 & 6582 & 5936 & 1683 & 500 & 52 & 50 & 49 & 49.5 \\
\hline 20.00 & 6134 & 6293 & 5634 & 1415 & 500 & 49 & 47 & 47 & 47 \\
\hline 21,00 & 6553 & 6655 & 6053 & 1354 & 500 & 48 & 47 & 46 & 46.5 \\
\hline 22.00 & 6327 & 6383 & 5827 & 1224 & 500 & 48 & 46 & 46 & 46 \\
\hline 23.00 & 6365 & 6494 & 5865 & 930 & 500 & 48 & 46 & 45 & 45.5 \\
\hline$|24.00|$ & 6433 & 6523 & 5933 & 960 & 500 & 48 & 46 & 46 & 46 \\
\hline
\end{tabular}

Tabel Data Teknik PLTU Sumbawa Barat Unit 2

\begin{tabular}{|c|c|c|c|c|c|c|c|c|c|}
\hline \multicolumn{10}{|c|}{ PLTU Unit2 } \\
\hline & \multicolumn{5}{|c|}{ Power Generator } & \multicolumn{3}{|c|}{ Transformator } & \multirow[b]{2}{*}{$\begin{array}{l}\text { Winding } \\
\text { Avg }{ }^{(C)}\end{array}$} \\
\hline & $\begin{array}{l}\text { PGros } \\
(\mathrm{kW})\end{array}$ & $\begin{array}{l}\text { PSemu } \\
\text { (kVA) }\end{array}$ & PNett (kW| & $\begin{array}{l}\text { PReactive } \\
\text { (kVar) }\end{array}$ & PAux $(\mathrm{kW})$ & $\begin{array}{l}\text { Oil Temp } \\
(\mathrm{PC})\end{array}$ & $\begin{array}{c}\text { LV Winding } \\
\left({ }^{\circ} C\right)\end{array}$ & $\begin{array}{c}\text { HV Winding } \\
\left.{ }^{\circ} \mathrm{C}\right)\end{array}$ & \\
\hline 010 & 5407 & 5495 & 4907 & 1008 & 500 & 52 & 42 & 41 & 41,5 \\
\hline 02.0 & 5863 & 5912 & 5363 & 811 & 500 & 52 & 42 & 41 & 41,5 \\
\hline 03.0 & 5747 & 5812 & 5247 & 841 & 500 & 52 & 42 & 41 & 41,5 \\
\hline 04.0 & 6301 & 6343 & 5801 & 522 & 500 & 52 & 43 & 41 & 42 \\
\hline 05.0 & 6508 & 6585 & 6008 & 855 & 500 & 52 & 43 & 42 & 42,5 \\
\hline 06.0 & 6547 & 6551 & 6047 & 1008 & 500 & 53 & 43 & 42 & 42,5 \\
\hline 07.0 & 6126 & 6250 & 5626 & 967 & 500 & 53 & 43 & 42 & 42,5 \\
\hline 08.0 & 6391 & 6493 & 5891 & 1156 & 500 & 53 & 44 & 42 & 43 \\
\hline 09.0 & 6074 & 6210 & 5574 & 1278 & 500 & 55 & 45 & 44 & 44,5 \\
\hline 10.0 & 6116 & 6272 & 5616 & 1290 & 500 & 57 & 45 & 46 & 45,5 \\
\hline 11.0 & 4714 & 4800 & 4214 & 1306 & 500 & 63 & 47 & 46 & 46,5 \\
\hline 12.0 & 5443 & 5605 & 4943 & 1366 & 500 & 63 & 48 & 48 & 48 \\
\hline 13.0 & 5029 & 5291 & 4529 & 1570 & 500 & 62 & 49 & 49 & 49 \\
\hline 14.0 & 5437 & 5556 & 4937 & 1521 & 500 & 64 & 50 & 50 & 50 \\
\hline 15.0 & 5520 & 5714 & 5020 & 1447 & 500 & 60 & 50 & 50 & 50 \\
\hline 16.0 & 5330 & 5523 & 4830 & 1379 & 500 & 63 & 47 & 48 & 47,5 \\
\hline 17.0 & 5331 & 5566 & 4831 & 1446 & 500 & 58 & 47 & 46 & 46,5 \\
\hline 18.0 & 5397 & 5583 & 4897 & 1452 & 500 & 56 & 46 & 45 & 45,5 \\
\hline 19.0 & 5167 & 5364 & 4667 & 1486 & 500 & 56 & 46 & 45 & 45,5 \\
\hline 20.0 & 5355 & 5546 & 4855 & 1329 & 500 & 55 & 44 & 42 & 43 \\
\hline 21.0 & 5316 & 5397 & 4816 & 1361 & 500 & 58 & 47 & 46 & 46,5 \\
\hline 22.0 & 5344 & 5542 & 4844 & 1286 & 500 & 63 & 47 & 48 & 47,5 \\
\hline 23.0 & 5286 & 5417 & 4786 & 1019 & 500 & 52 & 41 & 42 & 41,5 \\
\hline 24.0 & 5524 & 5609 & 5024 & 1101 & 500 & 52 & 43 & 42 & 42,5 \\
\hline
\end{tabular}

\section{Perhitungan Rasio Pembebanan}

Berdasarkan data teknik diatas maka di dapatkan rasio pembebanan transformator unit 1 dan 2 PLTU Sumbawa Barat sebagai berikut :

Contoh Perhitungan PLTU Unit 1 Jam 01.00

$$
\begin{aligned}
K & =\frac{S}{S_{r}} \\
K & =\frac{6,518 M V A}{10 M V A} \\
K & =0,65
\end{aligned}
$$

Grafik Rasio Pembebanan PLTU Sumbawa Barat Unit 1

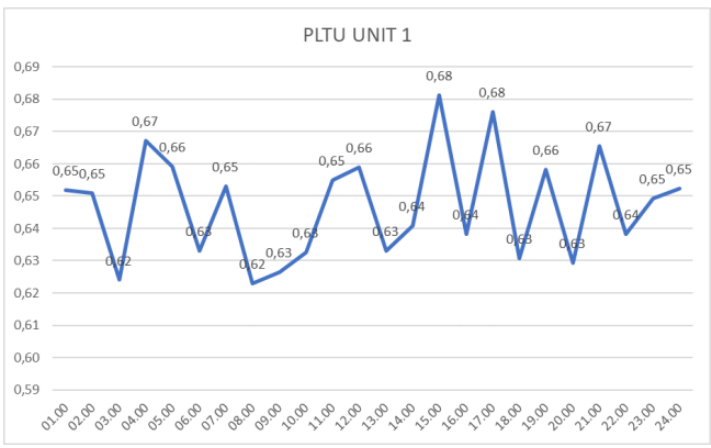

Grafik Rasio Pembebanan PLTU Sumbawa Barat Unit 2

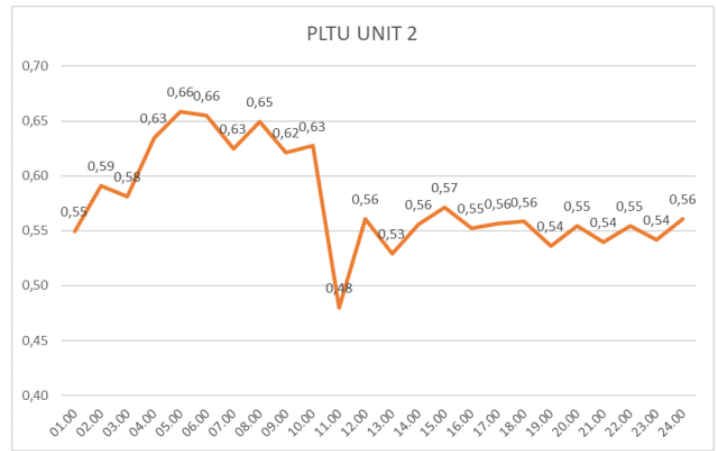

Berdasarkan hasil grafik rasio pembebanan diatas dapat dilihat bahwa trend beban di PLTU Sumbawa Barat Unit 1 lebih tinggi dibandingkan dengan Unit 2, hal ini dikarenakan Unit 1 baru saja dilakukan overhaul sehingga daya mampu dan ketahanan materialnya lebih baik. Pembebanan PLTU di sistem interkoneksi Sumbawa-Bima cenderung tidak dibebani maksimal karena sudah terdapat 2 buah PLTMG yang mempunyai daya mampu cukup besar.

\section{Perhitungan Susut Umur Transformator (Loss of Life)}

Setelah mendapatkan semua parameter selanjutnya untuk susut umur transformator (Loss of Life) dapat dihitung menggunakan rumus yang sudah dijelaskan sebelumnya. Susut umur transformator dikalkulasi dengan satuan jam per hari guna mengetahui pengurangan umur transformator setiap harinya. Adapun perhitungan susut umur transformator PLTU Sumbawa Barat Unit 1 dan 2 adalah sebagai berikut : Contoh Perhitungan PLTU Unit 1

$$
\begin{aligned}
& L= \frac{1}{N} \sum_{n=1}^{N} X_{n} \\
& 0,048+0,048+0,04+0,054+0,051+0,042+0,049+0,04+ \\
& 0,041+0,042+0,049+0,051+0,042+0,045+0,059+0,044+ \\
& L= 0,057+0,042+0,05+0,041+0,053+0,044+0,047+0,048 \\
& 24
\end{aligned}
$$


Tabel Hasil Perhitungan Susut Umur

Transformator PLTU Sumbawa Barat Unit 1 dan 2

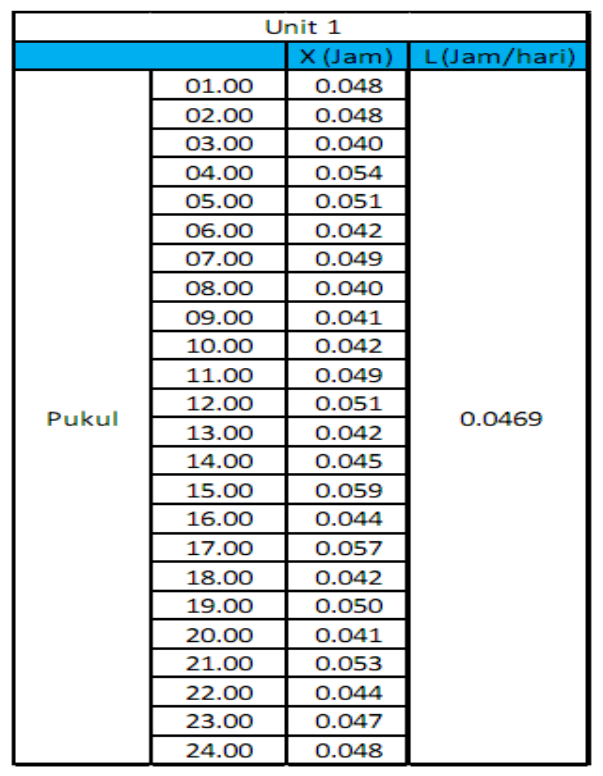

\begin{tabular}{|c|c|c|c|}
\hline \multicolumn{4}{|c|}{ Unit 2} \\
\hline & & $\overline{X(\mathrm{Jam})}$ & L (Jam/hari) \\
\hline \multirow{24}{*}{ Pukul } & 01.00 & 0.025 & \multirow{24}{*}{0.0311} \\
\hline & 02.00 & 0.032 & \\
\hline & 03.00 & 0.030 & \\
\hline & 04.00 & 0.043 & \\
\hline & 05.00 & 0.050 & \\
\hline & 06.00 & 0.049 & \\
\hline & 07.00 & 0.040 & \\
\hline & 08.00 & 0.047 & \\
\hline & 09.00 & 0.039 & \\
\hline & 10.00 & 0.041 & \\
\hline & 11.00 & 0.017 & \\
\hline & 12.00 & 0.027 & \\
\hline & 13.00 & 0.022 & \\
\hline & 14.00 & 0.026 & \\
\hline & 15.00 & 0.029 & \\
\hline & 16.00 & 0.026 & \\
\hline & 17.00 & 0.026 & \\
\hline & 18.00 & 0.026 & \\
\hline & 19.00 & 0.023 & \\
\hline & 20.00 & 0.026 & \\
\hline & 21.00 & 0.024 & \\
\hline & 22.00 & 0.026 & \\
\hline & 23.00 & 0.024 & \\
\hline & 24.00 & 0.027 & \\
\hline
\end{tabular}

Dari grafik diatas terlihat bahwa susut umur transformator pada PLTU Sumbawa Barat Unit 1 adalah 0,0469 Jam/hari sedangkan pada Unit 2 adalah 0,0311 Jam/hari. Hal ini diakibatkan oleh pembebanan pada Unit 1 yang lebih tinggi dibandingkan dengan Unit 2 yang hanya sekitar $60 \%$ dari pembebanan maksimal transformator.

\section{Perhitungan Efisiensi Transformator}

Daya keluaran dari transformator bisa didapatkan dari monitoring di Gardu Induk PLTU sedangkan daya masukan transformator bisa kita ambil dari Control Room PLTU Sumbawa Barat. Adapun perhitungan efisiensi transformator selama 24 jam adalah sebagai berikut :

Contoh Perhitungan PLTU Unit 1 Jam 01.00
$\eta=\frac{P_{\text {out }}}{P_{\text {in }}} \times 100 \%$

$\eta=\frac{5,7 M W}{6,43 M W} x 100 \%$

$\eta=88,59 \%$

Tabel hasil perhitungan efisiensi PLTU Sumbawa Barat Unit 1 dan 2

\begin{tabular}{|c|c|c|c|c|c|c|}
\hline \multirow{2}{*}{} & GT 1 & GT 2 & Unit 1 & Unit 2 & \multicolumn{2}{|c|}{ Efisiensi (\%) } \\
\cline { 2 - 7 } & $P_{\text {out }}$ (MW) & $P_{\text {out }}$ (MW) & $P_{\text {in }}$ (MW) & $P_{\text {in }}$ (MW) & Unit 1 & Unit 2 \\
\hline 01.00 & 5,7 & 3,3 & 6,43 & 5,41 & 88,59 & 61,03 \\
\hline 02.00 & 5,6 & 4 & 6,41 & 5,86 & 87,35 & 68,22 \\
\hline 03.00 & 5,7 & 5,5 & 6,23 & 5,75 & 91,55 & 95,70 \\
\hline 04.00 & 5,9 & 5,7 & 6,65 & 6,30 & 88,68 & 90,46 \\
\hline 05.00 & 5,6 & 5,8 & 6,56 & 6,51 & 85,43 & 89,12 \\
\hline 06.00 & 5,4 & 5,8 & 6,31 & 6,55 & 85,61 & 88,59 \\
\hline 07.00 & 5,5 & 5,4 & 6,40 & 6,13 & 85,88 & 88,15 \\
\hline 08.00 & 5,7 & 5,6 & 6,13 & 6,39 & 93,03 & 87,62 \\
\hline 09.00 & 5,6 & 5,4 & 6,18 & 6,07 & 90,67 & 88,90 \\
\hline 10.00 & 5,8 & 4,2 & 6,21 & 6,12 & 93,34 & 68,67 \\
\hline 11.00 & 5,7 & 4 & 6,42 & 4,71 & 88,79 & 84,85 \\
\hline 12.00 & 5,7 & 4,5 & 6,46 & 5,44 & 88,25 & 82,67 \\
\hline 13.00 & 5,4 & 4,5 & 6,14 & 5,03 & 87,98 & 89,48 \\
\hline 14.00 & 5,6 & 4,8 & 6,25 & 5,44 & 89,60 & 88,28 \\
\hline 15.00 & 5,7 & 5 & 6,48 & 5,52 & 87,92 & 90,58 \\
\hline 16.00 & 5,6 & 4,9 & 6,18 & 5,33 & 90,64 & 91,93 \\
\hline 17.00 & 5,7 & 4,8 & 6,66 & 5,33 & 85,53 & 90,04 \\
\hline 18.00 & 5,5 & 4,8 & 6,16 & 5,40 & 89,31 & 88,94 \\
\hline 19.00 & 5,5 & 4,9 & 6,44 & 5,17 & 85,46 & 94,83 \\
\hline 20.00 & 5,3 & 4,8 & 6,13 & 5,36 & 86,40 & 89,64 \\
\hline 21.00 & 5,5 & 4,8 & 6,55 & 5,32 & 83,93 & 90,29 \\
\hline 22.00 & 5,8 & 4,7 & 6,33 & 5,34 & 91,67 & 87,95 \\
\hline 23.00 & 5,6 & 4,8 & 6,37 & 5,29 & 87,98 & 90,81 \\
\hline 24.00 & 5,5 & 4,9 & 6,43 & 5,52 & 85,50 & 88,70 \\
\hline
\end{tabular}

Grafik efisiensi selama 24 jam di PLTU Sumbawa Barat Unit 1

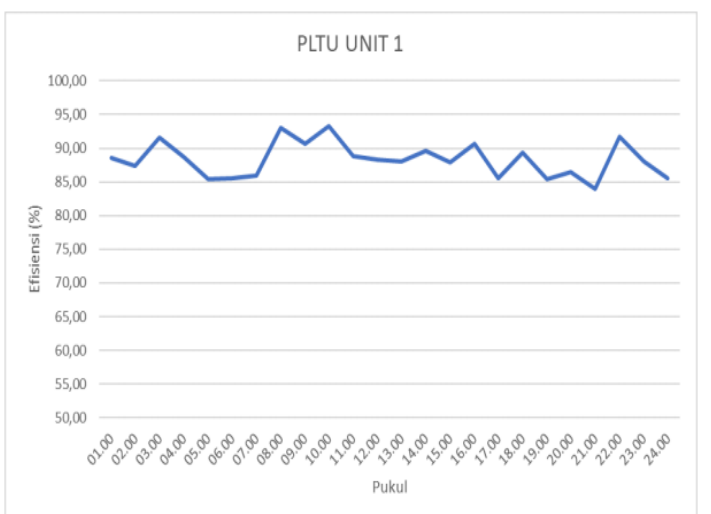

Grafik efisiensi selama 24 jam di PLTU Sumbawa Barat Unit 2

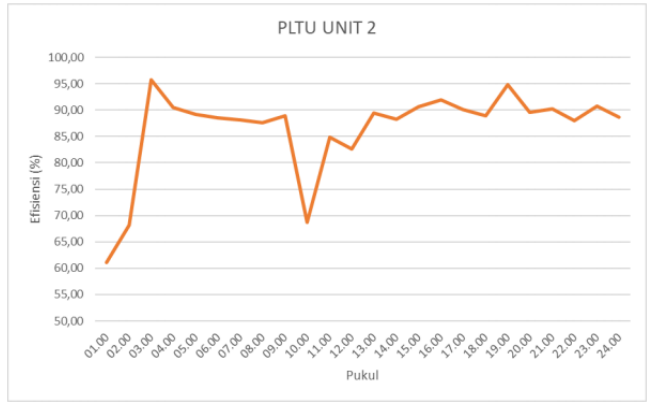


Pada grafik diatas terlihat bahwa efisiensi transfomator PLTU Sumbawa Barat Unit 1 dan 2 berbeda. PLTU Unit 1 cenderung memiliki efisiensi yang konstan sedangkan Unit 2 menunjukkan efisiensi yang naik dan turun seiring dengan kebutuhan beban oleh konsumen. Efisiensi pada PLTU Unit 2 di angka 61,03\% sedangkan efisiensi terbesar ada di angka $95,7 \%$. Untuk Unit 1 efisiensi terkecil di angka 83,9\% dan terbesar di angka 93,3\%. Pembebanan pada PLTU Sumbawa Barat memang berfluktuatif karena mayoritas konsumen adalah rumah tangga.

\section{PENUTUP}

\section{Kesimpulan}

Kesimpulan yang didapatkan dari hasil analisis pengaruh pembebanan terhadap efisiensi dan susut umur transformator step up $6 \mathrm{kv} / 70 \mathrm{kv}$ di PLTU Sumbawa Barat unit 1 dan 2 adalah sebagai berikut:

1. Efisiensi tertinggi PLTU Unit 1 ada di angka 93,3\% dengan output daya 5,8 MW dan daya input 6,21 MW sedangkan yang paling rendah ada di angka 83,9\% dengan output daya 5,5 MW dan daya input 6,55 MW. Efisiensi tertinggi PLTU Unit 2 ada di angka 95,7 \% dengan output daya 5,5 MW dan daya input 5,75 MW sedangkan yang paling rendah ada di angka $61,03 \%$ dengan output daya 3,3 MW dan daya input 5,41 MW. Pembebanan transformator tidak ada yang berada dibawah angka $60 \%$ karena apabila ada yang berada dibawah $60 \%$ maka lebih baik menggunakan transformator dengan kemampuan daya yang lebih kecil. Besar kecilnya pembebanan tidak berpengaruh terhadap efisiensi transformator, akan tetapi perbedaan efisiensi ini tergantung dari losses yang terjadi di dalam transformator, makin besar losses maka efisiensi transformator semakin kecil.

2. Susut umur transformator Unit 1 PLTU Sumbawa Barat adalah 0,0469 jam/hari dengan rata-rata beban $5,8 \mathrm{MW}$ sedangkan untuk Unit 2 adalah $0,0311 \mathrm{jam} / \mathrm{hari}$ dengan rata-rata beban 5,2 MW. Besar kecilnya susut umur transformator tergantung dari pembebanan yang diberikan, makin besar beban maka makin besar pula susut umurnya. Dalam hal ini memang untuk Unit 1 dibebani lebih tinggi daripada Unit 2 sehingga terlihat bahwa susut umur transformator Unit 2 lebih kecil.

3. Beban optimal pada PLTU ada di posisi $80-85$ $\%$ dari daya mampunya. Untuk Unit 1 sudah memenuhi syarat dengan beban 6,21 MW keluaran dari generator yang mempunyai efisiensi transformator cukup baik. Untuk Unit 2 masih banyak pembebanan yang dibawah $80 \%$ bahkan sampai $65 \%$ dari daya mampunya.

\section{Saran}

Berdasarkan hasil penelitian dan kesimpulan yang sudah ditarik, maka adapun saran yang bisa diberikan antara lain:

1. Operator PLTU Sumbawa Barat baiknya melakukan pemerataan dan pengoptimalan beban di posisi $80-90 \%$ dari daya mampu untuk PLTU, baik Unit 1 maupun Unit 2 agar tidak terjadi timpang antara kapasitas transformator dengan daya yang diproduksi.

2. Bagi Tim Pemeliharaan PLTU Sumbawa Barat, untuk sebaiknya melakukan pemeliharaan transformator secara rutin guna mengurangi losses yang terjadi. Apabila memungkinkan, fungsikan pendinginan secara ONAF meskipun beban tidak maksimal.

3. Bagi peneliti selanjutnya yang ingin melakukan peneltian terkait, disarankan untuk berfokus terhadap kerugian yang terjadi di dalam transformator itu sendiri guna memperbaiki efisiensi transformator.

\section{REFERENSI}

Choiri, E.S.A. 2017. Analisis Pengaruh Pembebanan Terhadap Efisiensi Transformator 20kV/150 kV di PLTU Cilacap Unit $1 \& 22 \times 300$ MW PT. Sumber Segara Primadaya Cilacap. Surakarta: Fakultas Teknik, Universitas Muhammadiyah Surakarta.

Ervianto, E., Rizki, Y.Y. (2019). Perkiraan Umur Transformator Berdasarkan Pengaruh Pembebanan Dan Temperatur Lingkungan Menggunakan Metode Trend Linear. Riau: Teknik Elektro, Fakultas Teknik, Universitas Riau.

Erwansyah. 2013. Bagian-Bagian Transformator dan Fungsinya (Online). (http://erwansyah19.blogspot.com)/ diakses pada 4 Mei 2020.

Gianto, A.S., Irianto, C.G., Gianto, D., (2015). Perhitungan Penurunan Umur Transformator Akibat Pengaruh Suhu Lingkungan. JETri. Vol. 13; No. 1, Hal. 15-36.

Herawati, A. Sofyan. 2015. Pengaruh Pembebanan Terhadap Efisiensi dan Usia Transformator (Studi Kasus Transformator IV Gardu Induk Sukamerindu Bengkulu) Berdasarkan Standar IEC 60076-7. Bengkulu: Teknik Elektro, Universitas Bengkulu.

Idschool. (2018). Transformator: Perbedaan Trafo Step Up dan Step Down (Online). (idschool.net/smp/transformatorperbedaan-trafo-step-up-dan-step-down/), diakses pada 20 April 2020.

International Electrotechnical Comission. (1972). Loading Guide For Oil Immersed Transformer. Geneva: IEC Publication. 
Kodoati, K.A. (2015). Analisa Perkiraan Umur Transformator. Manado: Fakultas Teknik Universitas Sam Ratulangi.

Lumbanraja. (2012). Transformator (Online). (https://lumbanrajateddy. wordpress.com /2012/ 03/07/transformator/), diakses tanggal 04 Juni 2020.

Srinivasan \& Krishnan. (2012). Prediction of Transformer Insulation Life with an Effect of Environmental Variables, International Journal of Computer Applications Vol. 55 No 5 .

PT PLN (Persero). (2010). Buku Pedoman Trafo Tenaga. Jakarta Selatan: PT PLN (Persero).

PLTU Sumbawa Barat. (2019). Manual Handbook PLTU Sumbawa Barat. Mataram: PT. PLN (Persero)

Muzar, M.A. Syahrizal. \& Syukri, M. 2018. Analisis Pengaruh Suhu Akibat Pembebanan Terhadap Susut Umut Transformator Daya Di Gardu Induk Lambaro. Banda Aceh: Teknik Elektro dan Komputer, Fakultas Teknik Universitas Syiah Kuala.

Najdenkoski, K. dkk. (2007. Thermal Aging of Distribution Transformers According to IEEE and IEC Standards. Berlin: IEEE Publication.

Nugroho. (2019). Sistem Pendingin Transformator: Pemasangan Kipas Transformator Hyundai GIS Kiaracondong (Online). (https://catatanwsn.wordpress.com/2019/04 /05/sistem-pendingin-transformatorpemasangan-kipas-transformator-hyundaigis-kiaracondong), diakses pada $119 \mathrm{Mei}$ 2020.

Odinanto, T. (2014). Analisis Pengaruh Pembebanan Terhadap Usia Transformator Distribusi Di PT. PLN Distribusi APJ Gresik. Surabaya: Teknik Elektro, Institut Teknologi Adhi Tama.
Perera, K.B.M.I \& Lucas, J.R. (1999). Loading Of Transformers Beyond Nameplate Rating. Sri Lanka: University of Moratuwa.

Permana, A. (2020). Transformator Bagian 1 : Pengertian dan Prinsip Kerja (Online). (https://www.alifpustaka.com/transformato r-bagian-1-pengertian-dan-prinsip-kerja/). diakses tanggal 21 April 2020.

Purnama, S. 2011. Analisa Pengaruh Pembebanan Terhadap Susut Umur Transformator Tenaga (Studi Kasus Trafo GTG 1.3 PLTGU Tambak Lorok Semarang). Semarang: Teknik Elektro Universitas Diponegoro.

Skemaku (2015). Jenis-Jenis Trafo Pada Rangkaian Elektronika (Online). (https://skemaku.com/jenis-jenis-trafopada-rangkaian-elektronika/), diakses pada tanggal 02 Juni 2020.

Tambunan, J.M,. Hariyanto, A., Tindra, W.K.. (2015). Kerja Pembebanan Dan Temperatur Terhadap Susut Umur Transformator Tenaga 150/20 kV MVA. Jurnal Sutet Vol.5 No.2.

Utomo, P. (2019). Studi Analisis Kualitas Transformator Daya Gardu Induk 150 KvSiantan. Tanjungpura: Teknik Elektro, Fakultas Teknik Universitas Tanjungpura.

Warman, E., Junedy, P. (2013). Studi Pengaruh Pembebanan Terhadap Susut Umur Transformator Daya (Aplikasi Pada Gardu Induk PematangSiantar). Jurnal Singuda ENSIKOM Vol.3 No.1.

Wijaya, M. 2001. Dasar-Dasar Mesin Listrik. Jakarta: Djambatan

Zuhal. 1995. Dasar Teknik Tenaga Listrik dan Elektronika Daya, Jakarta: Gramedia 